Bol. Mus. Para. Emilio Goeldi. Ciências Humanas, Belém, v. 1, n. 2, p. 11-21, maio-ago. 2006

\title{
Pescadores de Sonhos: um olhar sobre as mudanças nas relações de trabalho e na organização social entre as famílias dos pescadores diante do veraneio e do turismo balnear em Salinópolis, Pará1 \\ Dream catchers: labor relations and social change among fisherman families due to summer vacations and beach tourism in Salinópolis, Pará
}

Resumo: A atividade balnear e turística de Salinópolis, região do Salgado Paraense, tem desencadeado importantes transformações na organização social e espacial do lugar através de um processo acelerado de valorização e especulação imobiliária em função da 'segunda residência' de veranistas. A população local, composta essencialmente por pescadores tradicionais e pequenos produtores rurais, frente ao processo de turistificação balnear, passa a privilegiar os trabalhos como o dos 'caseiros' nas propriedades dos veranistas e outros voltados para o balneário, incorporando novas formas de se relacionar com o mundo, sem, contudo, abandonar o seu modus vivendi povoado por seres encantados e explicado pela força da natureza. $\bigcirc$ olhar desta pesquisa centra-se na vida familiar e sociocultural dos moradores do bairro da Prainha, que foram remanejados do centro para a periferia da cidade em função do zoneamento urbano balnear, focalizando a mudança nas relações de trabalho da pesca para os trabalhos de caseiros e outros voltados para o veraneio e, como essas mudanças redefinem o cotidiano destes moradores, provocando transformações nas formas de organização social. Os 'Pescadores de Sonhos' são estas familias de pescadores artesanais que gradativamente abandonam o trabalho da pesca na sua forma tradicional, para partirem em busca de inúmeras outras atividades voltadas para o comércio balnear, na expectativa de melhorar de vida.

Palavras-chave: Organização social e política. Impacto do turismo. Mudanças. Profissões.

Abstract: The resort and tourist activity in the city of Salinópolis, Salgado Region of Pará, has brought a lout important transformation in the social and spatial organization of the place, through an accelerated valorization and land speculation in second residences (summer residences) of people on vacation and tourists. The local population, composed of traditional fishermen and small rural producers, in front of the tourist invasion process, preferring works as housekeepers in summerhouses incorporating new ways of relations with the world. Though, without abandoning their modus vivendi habited by enchanted beings and explained by nature force. The objective of this research is the center of attention in family and social-cultural life of the natives of Prainha, who was transfers the city center for periphery, giving focus on changes in working relations between fishermen families and how these changes that involve the men and the many manifestation forms of nature, defining the quotidian these dwellers, causing some changes in the local system. The 'Fishers of Dreams' are these fishermen and their families that, slowing abdicate, leave fishing in it's traditional form, to search for many others activities centered on the summer market, expecting to improve quality of life.

Keywords: Social and political organization. Impact of the tourism. Changes. Professions.

\footnotetext{
1 Este artigo apresenta, em síntese e com o mesmo título, a Tese de Doutorado defendida em novembro de 2003 no Instituto de Filosofia e Ciências Humanas da Universidade Estadual de Campinas.

I Museu Paraense Emílio Goeldi. Pesquisadora associada ao Grupo Renas. Belém, Pará, Brasil (deadriao@ig.com.br).
}

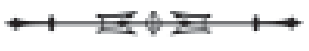




\section{INTRODUÇÃO}

Focalizou-se o processo de transformação e mudança de uma população tradicionalmente constituída de pescadores artesanais ${ }^{2}$, frente à vida balnear a que estão expostos na cidade de Salinópolis. Esta população, tradicionalmente em contato com a vida mais simples e dependente dos recursos da natureza ligados à pesca artesanal, passa a conviver com os costumes introduzidos pelo fluxo de veranistas que solicitam os serviços destes pescadores para atividades ligadas ao mundo balnear. Neste sentido, pretendese observar até que ponto essas solicitações interferem de maneira mais ampla nas formas de organização social, nas relações entre o homem e a natureza e como as mudanças sociais são incorporadas e (re)contadas através das histórias dos encantados ${ }^{3}$. E, a partir deste olhar, contribuir para o avanço dos estudos dedicados à compreensão do modo de vida tradicional e das transformações que hoje em dia afetam a vida e o destino de famílias como as dos pescadores artesanais da região do salgado paraense.

Esta é uma região que vive o 'encontro de sociedade' não nos modelos de Galvão (índio e branco), mas no sentido de sociedade cabocla e de pescadores tradicionais com uma população flutuante de veranistas e turistas, confrontando formas de vida tradicionais com formas 'modernas'.

Salinópolis pertence à microrregião do Salgado paraense (litoral norte do estado do Pará). É uma região balnear oceânica de veraneio dos mais concorridos e requintados do Nordeste paraense, recebendo veranistas e turistas das mais diversas localidades. Por isso, tem sido palco, nas últimas décadas, de uma série de mudanças através de processos usualmente definidos como urbanização e 'turistificação's. Lugar privilegiado para uma análise sobre as múltiplas estratégias e mecanismos que as formas tradicionais de organização social de produtores, como a das famílias dos pescadores-lavradores da região, acionam e utilizam para a sobrevivência.

Esta região é integrada por dez municípios: Colares, Curuçá, Magalhães Barata, Maracanã, Marapanim, Primavera, Salinópolis, Santrém Novo, São Caetano de Odivelas e Vigia. Possui cerca de 500 km de extensão e está situada entre a baía do Marajó (0॰30’ 40 WGr.) e a baía do Gurupi (0॰30’46 WGr.). Compõe um grande sistema de rios que se estendem desde a margem direita do estuário amazônico (Vigia), no estado do Pará, até a baía de Tubarão (Ponta de Mangue), no estado do Maranhão.

\footnotetext{
2 Termo genérico empregado oficialmente por várias instituições ligadas à pesca (Confederação Nacional dos Pescadores, Federação Estadual dos Pescadores, Colônia dos Pescadores, Pastoral da Pesca e, certamente, outras instituições), que expressa a atividade pesqueira cujo manejo dos recursos naturais é feito através de tecnologia simples, com instrumentos totalmente ou parcialmente feitos pelo próprio pescador com recursos locais.

3 A reflexão sobre as representações em torno da categoria (encantado), em Salinópolis, é aqui realizada à luz de Galvão (1955), que se refere às próprias considerações locais sobre o que é encantado, isto é, uma força mágica atribuída aos fenômenos sobrenaturais capaz de 'encantar' seres humanos, animais e objetos. A existência de um 'mundo encantado' faz parte de um sistema de crenças, característico na região Amazônica, um mundo povoado por lendas e histórias que explicam e procuram dar conta da vida local.

4 'Vida tradicional', no sentido aqui referido, é o modo de vida mais simples diretamente ligado aos recursos da natureza e dela mais dependente; ao contrário, a forma de 'vida moderna' é fruto principalmente de uma ordem econômica capitalista caracteristicamente expansionista, que não se expande apenas em termos espaciais, mas também em inovações tecnológicas e aumento de produtividade. Para maior reflexão, consutar Bourdieu (1983), Geertz (1998), Giddens (2001), Brabha (2001), entre outros.

5 Expressão freqüentemente utilizada por especialistas e estudiosos do turismo, correspondendo ao crescente movimento do turismo na sociedade moderna. Para maiores informações, consutar Krippendorf (1989), Madruga (1992), Macedo (1993), Yázigi (1999); Rodrigues (2000).
}

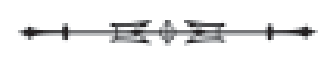


Apresenta-se entrecortada em ilhas, penínsulas e baías, situadas nas desembocaduras dos rios de curto percurso, mas muito amplas. Nela predominam formações de falésia, praias e sedimentos arenosos e silicos, mangues, dunas e restingas (FRANZINELL, 1992). É potencialmente região de turismo, mesmo que ainda incipiente.

Salinópolis é, na região, o catalisador deste fenômeno, recebendo grande fluxo de veranistas e turistas que passam a conviver com a população. Como a forma de turismo focalizada neste trabalho é o 'turismo balnear', a periodicidade destes veranistas, que freqüentam o balneário costumeiramente nas épocas de férias e feriados prolongados, provoca maior proximidade com os moradores locais através das relações de trabalho como o de caseiro, por exemplo, e através de novas relações de reciprocidade, vizinhança e compadrio, envolvendo, de algum modo, os moradores locais com os veranistas.

A região do Salgado paraense mostra-se cada vez mais importante para pesquisas antropológicas frente ao processo de transformação e mudança pelo qual está passando. Neste sentido, o problema da 'tradição e mudança' na pesca artesanal está presente em vários trabalhos $^{6}$. Entretanto, sobre os estudos de populações ribeirinhas e costeiras na região Norte, constata-se, ainda, pouca discussão sobre o processo de mudança advindo com a presença do balneário e do turismo nestas populações - mais recentemente é que tais estudos constituem objeto de pesquisa.

Porém, a questão central deste estudo não é o turismo, mas o que ele provoca no modo de vida das familias de pescadores que se voltam a esse tipo de atividade, ou seja, as mudanças provocadas pelo implemento do turismo balnear na vida tradicional dos pescadores locais. Desta forma, o turismo é visto como um dos principais agentes de transformação e mudança na vida local. Por esta razão é que o 'fenômeno do turismo' tornou-se um objeto desta investigação antropológica. A ênfase do estudo consiste na observação das transformações sociais acarretadas pelas mudanças nas relações de trabalho da pesca artesanal para serviços de interesse balnear como mudança de logradouro espaço sociofamiliar; mudança nas relações com a vizinhança; mudança na relação de parentesco, nas redes de solidariedade, afinidade e compadrio; na organização da vida comunitária do bairro, festas, rituais e crenças, mutirões etc.

A contribuição e a especificidade deste trabalho consiste, num certo sentido, em analisar como a mudança nos sistemas de pesca - oriunda da mudança nas relações de trabalho - transformaram o sistema de relações sociais. Trata-se de uma análise antropológica sobre o processo de mudança por qual passam as famílias de pescadores do bairro da Prainha, que gradativamente abandonam a pesca e se voltam para os trabalhos solicitados com a presença do veraneio e do turismo balnear.

$\bigcirc$ 'turismo balnear' é uma das formas de turismo mais evidenciadas na região realizada pelos 'veranistas' que são, em geral, proprietários de casas de veraneio (como segunda residência) e sazonariamente estão no balneário. Já mantêm uma certa familiaridade e proximidade com a vida local. São diferentes de outros 'turistas' que passam em caravanas, conhecendo ou

\footnotetext{
6 Ver produção científica sobre comunidades pesqueiras na Amazônia: IDESP; SPEVEA - SUDAM; Projeto RENAS - Museu Goeldi, etc. Na área da Antropologia da Pesca: Furtado (1987), Nascimento (1993) no Goeldi ; Maués (1990, 1995); Motta-Maués (1993, 1999); Penner (1984); Mello (1985) Maneschy (1990,1994), na UFPA., entre outros. A continuidade desta tradição na Antropologia está evidenciada nas pesquisas atuais que estão culminando em Dissertações e Teses, realizadas por: Denise Cardoso (UFPA); Gercilene Costa (UFPA); Madian Pereira (UFPA); Denize Adrião (UNICAMP); Wilma Leitão (UFRJ); entre outros.
}

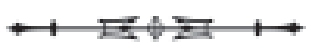


visitando lugares pitorescos em poucos dias e que mantêm pouco ou nenhum laço com a população local e a cidade. $O$ termo 'turismo balnear' é aqui construído para caracterizar o turismo, o veraneio e o balneário em Salinópolis, distinguindo-o de formas manifestadas em outras áreas.

Como atividade multidimensional, que tem como principal matéria-prima os recursos naturais, históricos e culturais, o turismo constitui-se em um fenômeno das sociedades contemporâneas, marcadas pela crescente busca de recuperação dos desgastes físicos e mentais do cotidiano urbano-capitalista (RODRIGUES, 1999). O fenômeno contemporâneo do turismo coloca-se como vetor contraditório e emblemático neste processo: acentua a produção de lugares de consumo e o consumo de lugares ${ }^{7}$.

Com estas potencialidades, o turismo, além de suscitar estudos e reflexões, se estabelece em um espaço de disputas políticas e econômicas entre governos, prefeituras, instituições públicas e particulares etc., tendo nos discursos ecológicos ou pseudo-ecológicos e na mídia seus principais canais de disseminação na sociedade. Deste modo, disputam seu mercado turístico em favor, na maioria das vezes, de uma comercialização estereotipada de espaços e culturas locais.

Constatou-se que a presença do 'turismo balnear' provoca certas mudanças nos sistemas locais: na organização social, nas relações dos homens entre si e nas relações que envolvem o homem e a Natureza, através das relações de trabalho e serviços que passam a ser requeridas pela presença do veraneio, atualizando, reafirmando ou reconstruindo uma nova identidade social diante de transformações produzidas, entre outras, pela presença freqüente dos veranistas nesta sede balnear.
Neste estudo, privilegia-se a vida familiar e sociocultural dos moradores do bairro da Prainha, porque é um bairro representativo da vida tradicional, onde moram pescadores artesanais e pequenos lavradores que compõem significativamente a 'gente do lugar'8. Essa população vem essencialmente do interior do município e, paulatinamente, está abandonando suas ocupações tradicionais para se envolver com trabalhos eventuais, voltados para o balneário. São famílias que acompanham de algum modo o crescimento da cidade, os processos de urbanização e de especulação imobiliária, consequentemente vivendo a expulsão e deslocamento do centro para a periferia.

Os moradores do bairro da Prainha são essencialmente pescadores e pequenos produtores rurais, oriundos do interior do município de Salinópolis e de outras regiões vizinhas, por isso guardam certas preferências e modo de vida particular que, entretanto, passam a mudar com a presença do veraneio e turismo balnear (Tabela 1).

Através das observações do modo de vida dos moradores no bairro da Prainha são feitas as reflexões sobre o processo de transformação e mudança. É na vida cotidiana do bairro que está evidenciado o contraste entre o modo de vida tradicional e a vida balnear. É importante enfatizar que essas famílias vivenciam o processo de transição em que se mesclam traços da cultura e da vida tradicional com a 'modernidade' (identificada pela mudança nas relações de trabalho da pesca para o de caseiro e outros serviços voltados para o balneário): hábitos, costumes e valores de fora são incorporados e, muitas vezes, passam a ser privilegiados especialmente pelos mais jovens (Tabela 2).

\footnotetext{
7 Luchiari (1999) e Serrano (1999) também discutem este aspecto negativo do trabalho voltado para o turismo.

8 'Gente do lugar' é uma expressão tirada da fala de um morador do bairro da Prainha, quando se referia à pessoa pertencente ao lugar. Lugar, aqui compreendido, como porção do ambiente transformada pela ocupação, pelo uso e, sobretudo, repleto de significação social, que indica quem pertence, quem não pertence, quem e em que circunstâncias faz parte do bairro.
}

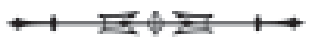


Tabela1. Localidades dos municípios de onde migraram os chefes dos grupos domésticos moradores do bairro da Prainha (1999-2000).

\begin{tabular}{lc}
\hline Origem & Número de Moradores \\
\hline Ajuruteua *** (Bragança) & 1 \\
Augusto Corrêa**** & 1 \\
Bragança (cidade) & 1 \\
Capanema & 3 \\
Castanhal*** & 2 \\
Coremas (Salinópilis) & 3 \\
Cuiarana (Salinópilis) & 4 \\
Curuçá & 2 \\
Derrubadinho (Salinópilis) & 2 \\
Fortaleza (Ceará) & 1 \\
Igarapé-Açu** (Bragança) & 1 \\
Imperatriz (Maranhão) & 1 \\
Iraquara (Salinópilis) & 2 \\
Maracanã & 4 \\
Marituba & 1 \\
Marudá & 1 \\
Motta* (Maracanã) & 2 \\
Pirabas & 4 \\
Prata & 3 \\
Salinópolis (fora do bairro da Prainha) & 2 \\
Salinópolis (do bairro da Prainha) & 2 \\
Santo Antonio do Urindêua & 2 \\
São Bento & 4 \\
Sasua & 1 \\
\hline TOTAL & 50 \\
\hline Fonte: Tabato de Camo (199 &
\end{tabular}

Fonte: Trabalho de Campo (1999, 2000).

* Motta pertence à jurisdição de Maracanã, mas seus moradores se consideram pertencentes a Salinópolis.

*** Ajuruteua, Castanhal e Igarapé-Açu encontram-se na Zona Bragantina, mas os moradores dessas localidades não são chamados bragantinos.

****Augusto Corrêa é município desmembrado de Bragança.

Os moradores do bairro da Prainha, de origem mais interiorana, pescadores lavradores e essencialmente dependentes dos recursos da natureza, tradicionalmente apresentam relacionamentos e práticas sociais de trabalho mais solidários, realizados pelos companheiros, parentes e afins, mantendo uma rede de reciprocidade em torno da vizinhança.

Nos dias atuais, embora poucos moradores do bairro mantenham roça e pequena lavoura em sítios próximos, o seu cotidiano ainda lembra a vida rural, marcada pela solidariedade nas relações de trabalho centrada na pesca e nas relações entre a vizinhança.

"Aqui a gente vive entre parente. Aqui é tudo companheiro antigo de pesca, a maioria é cumpadre, é aparentado, trabalha junto. Nosso mundinho é esse - aqui a gente vai vivendo. O peixe num falta na mesa de nenhum pobre. Aqui ninguém passa fome. Aqui a maioria é comparsa da vida de pescá" (Chico, 66 anos, pescador, oriundo de Cuiarana).

"Nós vivemo aqui porque a nossa familia e os nossos parente também vive aqui. A gente já num pesca, não demo continuidade ao ofício dos nossos pais e avós pescadores. A gente está noutro ramo mas continua ligado de um modo ou doutro com os pescadores daqui. Tem alguns parentes que ainda pescam... A gente comerceia, esta nossa vendinha assisti a muita gente do bairro, do pão ao querosene... tem gente que num paga no dinheiro mas paga com prestação de produto, é peixe, é marisco... conforme o caso que interessá". (Mendes, 58 anos, comerciante, oriundo da Derrubada).

No comércio predominam as transações monetárias, entretanto, a troca entre produtos é bastante freqüente entre os regionais. É comum entre os moradores do bairro da Prainha um certo escambo. Produtos do mar e do interior, como frutas regionais, farinha de mandioca e derivados (beiju, polvilho, goma etc.), são vendidos e muitas vezes trocados em pequenas casas comerciais e nas feiras populares nos finais de semana (manhãs de sábado e domingo $)^{9}$. É igualmente comum que nestas feiras, junto com frutos e iguarias fabricadas e vindas do

\footnotetext{
9 Atualmente, o comércio se faz no Porto Grande, visivelmente mais intenso, com a presença de várias casas comerciais, do mercado municipal e da feira livre, onde os pescadores chegam das suas pescarias, pesam o peixe e colocam-no para comercialização; e no 'Terminalzinho' que, mais recentemente, tem cumprido esta função em virtude do crescimento da cidade em direção oposta ao centro da cidade.
}

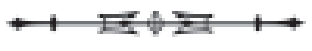


Pescadores de sonhos: um olhar sobre as mudanças nas relações de trabalho...

Tabela 2. Razões da mudança do tabalho da pesca para outros trabalhos voltados para o veraneio.

\begin{tabular}{ll}
\hline Trabalho da pesca & Trabalho de caseiro e outros voltados para o veraneio \\
\hline Falta de condição (apetrechos e material próprio & Não necessita de material próprio \\
para realizar o trabalho) da pesca & para realização do trabalho \\
Sucateamento do material de pesca & As condições de trabalho são alheias \\
Conhecimento especíico, aptidão e coragem & Não necessita de conhecimento específico, aptidão ou coragem \\
Muito esforço, trabalho pesado & Pouco esforço, trabalho leve \\
Concorrência de mercado & Concorrência \\
Perigo/Imprevisibilidade & Não corre perigo/certa rotina \\
Dificuldade de armazenamento e venda & Trabalho certo/pagamento certo \\
Remuneração pequena e incerta & Remuneração maior e certa (salário) \\
Degradação ambiental e afastamento dos cardumes/ & Independe diretamente das condições ambientais \\
dependente das forças da natureza & \\
Pouco tempo com a família & Mais tempo com a família \\
Satisfação/Identificação & Insatisfação/ não identificação \\
Autonomia & Sem autonomia \\
Não proporciona ascensão social & Proporciona ascensão social \\
Não favorece com regalias e moradia & Favorece com certas regalias e moradia \\
\hline
\end{tabular}

interior, também se encontrem remédios caseiros, raízes, óleos, paus, folhas etc., que são largamente utilizados e não encontrados com facilidade. Desta forma, os moradores da Prainha mantêm conexões com o interior no que se refere à produção econômica e ainda conservam um intercâmbio alimentar, favorecendo certa dieta que, provavelmente, se reflete no estado de saúde e de longevidade destes moradores (Figura 1), onde já é observada a introdução de outros tipos de alimentos, que marcam o processo de mudança vivido.

"Do sítio a gente traz farinha, beiju, curadá e uma porção de coisa que a gente produz por lá; Quando é tempo, também a gente traz fruta... aquelas que a gente num encontra mais por aqui, as do mato: taperebá do sertão, cajarana, ingá, buriti, taperoba, caju e mais alguma que num me lembro. Às vez a gente até vende para os barão que vêm veraneá" (Ana, 58 anos, dona de casa, oriunda de Água Boa).
Em função do veraneio, do consumo de certos produtos apreciados pelos veranistas, os produtos do 'sítio' - como a população local se refere aos produtos vindos do interior - tendem a diminuir em função da demanda dos veranistas por outros produtos. A produção passa a privilegiar o mercado para os consumidores veranistas. Por essa razão, os produtos vendidos nas feiras se diversificam. Alguns produtos passam a ser freqüentes e outros nem sempre, em virtude da possibilidade de comercialização mais rentável com os veranistas. Observa-se que certos frutos e iguarias, presentes normalmente nestas feiras, somem no veraneio ${ }^{10}$, dando lugar aos de preferência e comercialização na estação balnear, a exemplo das frutas (maça, pêra, melão, morango) e dos legumes e verduras variados (couve-flor, espinafre, repolho, tomate etc).

\footnotetext{
${ }^{10}$ O período de veraneio mais cobiçado é o mês de julho, que coincide com as férias escolares e com o período de sol mais intenso na região. O período das festas de final de ano, só mais recentemente, tem atraído os veranistas para as comemorações ocorridas na praia, pois, é período de muitas chuvas.
}

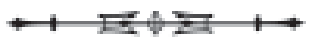


"Quando é tempo de veraneio é tudo uma caristia, se encontra muita coisa mas tudo é do gosto do turista, só tem coisa pros veranista comprá. O que é bom mesmo, o que é da gente fica mais vasqueiro, acaba rápido. Os vendedô investe mais no que vende pro veranista, num gasta tempo com as coisa que só o pessoal daqui vai apreciá" (Manoela, 58 anos, marisqueira, oriunda de Santa Rosa).

Observou-se que a despeito do movimento em outras áreas da cidade, em função da vida balnear em que há casas de veranistas, a vida dos moradores

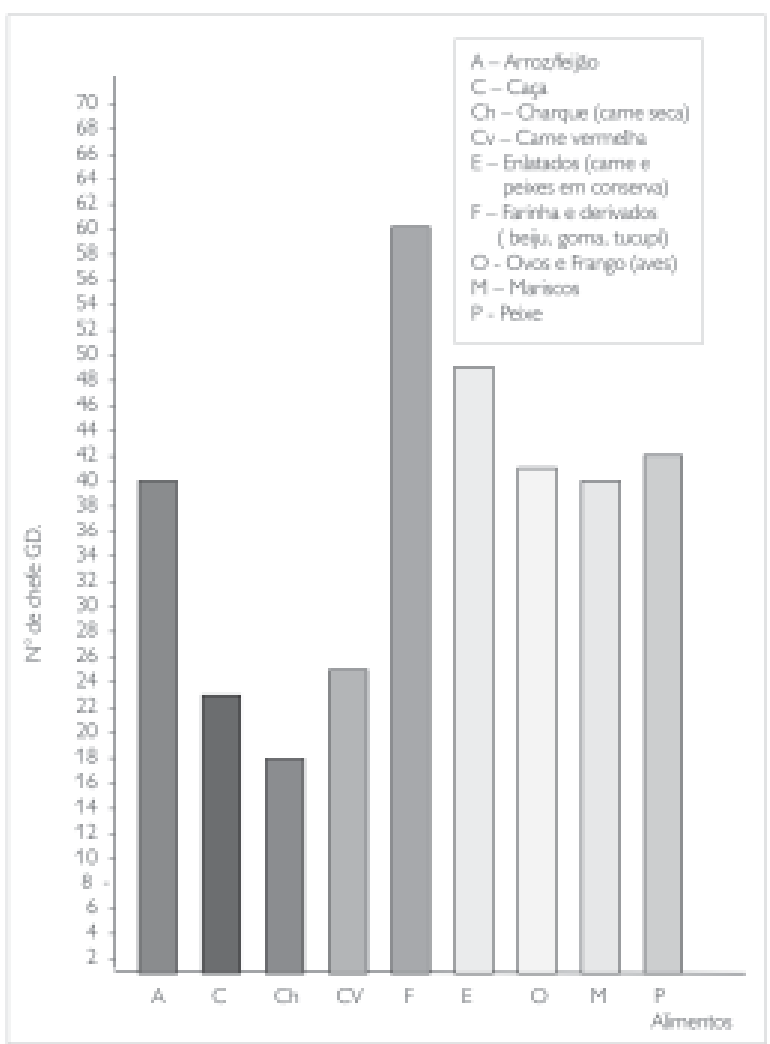

Figura 1. Gráfico da preferência alimentar dos moradores do bairro da Prainha. no bairro da Prainha é pacata, pois não há outro movimento senão o dos próprios moradores locais. A chegada dos pescadores do mar, com o pescado, é o motivo de maior movimento, principalmente com relação às crianças, que acompanham os pescadores pelas ruas até chegarem em casa.

Neste aspecto, o bairro constitui-se num mundo particular em que se mesclam, de um lado, a vida mais simples - tradicional e mais dependente dos recursos da natureza, como a pesca artesanal, o fabrico dos currais e das moradias, por exemplo e outros hábitos e costumes que preservam uma forma própria de relacionamento mais solidário com a vizinhança, com as pessoas entre si e com a natureza. Podem ser destacados, desde a preferência, a forma e o preparo de certos alimentos até os cuidados com a saúde através da prática de cura da medicina caseira etc., que, tradicionalmente, são atividades partilhadas pelos membros da família ou comunidade do bairro ${ }^{11}$. $E$, de outro lado, a vida balnear, a vida como caseiros e como biscateiros que são mais individualizados, em função do balneário e dos veranistas. A medida em que passam a se envolver com a vida do veraneio e com o comércio balnear o ritmo muda, incorporando relações mais individualistas e de ganho particular.

Observou-se que, no bairro da Prainha, onde, eminentemente, encontram-se famílias de pescadores artesanais com poucos recursos pesqueiros, não sindicalizados e que raramente têm a possibilidade de concorrer com a pesca comercial mais aparelhada, o envolvimento com o veraneio tem crescido. Em decorrência deste envolvimento, estas famílias distanciam-se do modo de vida tradicional da pequena pesca, da

\footnotetext{
${ }^{11}$ Como relacionamentos e práticas sociais mais solidárias tradicionalmente realizadas pelos moradores da Prainha estão: o trabalho da pesca, realizado pelos companheiros, parentes e afins; e o trabalho das parteiras e 'mães-de-leite' ou de peito entre parteiras, comadres e vizinhas; também estão inclusas as benzedeiras; e o trabalho da mariscagem, pequena pesca de mariscos realizada na beira, especialmente de mexilhão e sarnambi, entre a parentela feminina (filhas, noras, irmãs, comadres, vizinhas etc).
}

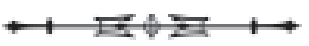


agricultura familiar, da vizinhança do bairro e de tudo o que lhes era peculiar, passando a se dedicar cada vez mais aos trabalhos voltados para o veraneio e para o turismo balnear.

\section{À GUISA DE CONCLUSÃO}

Os moradores da Prainha são os mais antigos pescadores da região salinopolitana, que viveram o processo de deslocamento centro-periferia em função da urbanização balnear iniciada a partir das décadas de 1960 e 1970 com a implantação da Estância Hidromineral. São pequenos pescadores que venderam suas propriedades para a construção de 'segunda residência' dos veranistas e se deslocaram para a periferia da cidade, ocupando regiões de mangue aterrado, muitas vezes em condições insalubres. São estes pescadores que se envolvem, mais especialmente, com os trabalhos voltados para o turismo balnear em função de apresentarem menor poder de pesca.

Sem condição de concorrência com a pesca comercial, paulatinamente, a pesca tradicional vai sendo substituída por serviços derivados do veraneio e, entre estes, o trabalho de caseiro é o que mais atrai os moradores locais. Diversos fatores contribuíram para as mudanças nas relações de trabalho da pesca para os trabalhos com o veraneio: desde o sucateamento dos apetrechos de pesca (envelhecimento dos instrumentos de pesca e a não-substituição a contento) até a diminuição do pescado em função do distanciamento das regiões pesqueiras frente à pesca comercial, muito mais aparelhada e intensa.

Neste trabalho, através da pesquisa de campo, observou-se que o 'turismo balnear' apresenta-se como uma atividade econômica ascendente, de exploração econômica e social, que acabou por envolver os moradores locais. Todos, de uma forma ou de outra, relacionam-se com o turismo; desde o sujeito que pesca para o turista, passando ao que abriga o turista em sua casa, aluga a sua casa ou seu terreno para armarem barracas de camping ou comercializar comidas, até o indivíduo que vai ao bar somente para observar o movimento dos turistas.

Para os moradores da Prainha, os trabalhos com a vida urbana do veraneio são alternativas de sobrevivência frente às modificações sociais e econômicas enfrentadas. Para os moradores locais, o trabalho de caseiro é concebido como 'tranqüilo', pois o tipo de trabalho exercido dispensa especialidade e instrumentos de trabalho, atraindo os menos favorecidos; a razão custo $x$ benefício, menos perigoso, menos penoso, menos tempo de trabalho dispensado com garantia de pagamento contínuo o ano inteiro; e o prestígio que esta relação pode acarretar, pois ser caseiro de determinadas pessoas pode favorecer o crédito na praça comercial, entre outras (Tabela 1).

No que se refere às mudanças que de fato ocorreram devido à passagem do trabalho da pesca para o trabalho com o veraneio, concretamente, é possível dizer que, na própria organização social do trabalho, ocorreu uma mudança significativa que modificou todo o sistema de troca e solidariedade que envolvia o trabalho da pesca na vizinhança do bairro. Na pesca tradicional, exercida pelos moradores locais, o trabalho era coletivo: os apetrechos e sua conservação, bem como os frutos, eram partilhados pelos parceiros pescadores e seus familiares, por exemplo. Como o trabalho era exercido em parceria pelos vizinhos e afins, o tempo do trabalho e o tempo livre eram comuns e, freqüentemente, eram partilhados conjuntamente pelos parentes e afins, mantendo uma certa coesão entre a família e a vizinhança do bairro.

O trabalho com a pesca era antes exercido mais livremente no âmbito do bairro. Quando preparavam a pesca para o dia seguinte, tecendo as redes de pesca, também estabeleciam as redes sociais do bairro e da vizinhança (BECK,1989).

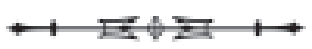


Com a mudança do trabalho da pesca para os trabalhos com o veraneio e para o mundo balnear, mudaram as relações de trabalho e as relações entre a vizinhança. $\bigcirc$ "ganho'12, que antes era, de certa forma, partilhado e até comemorado por todos os parentes e afins da vizinhança, atualmente passa a ser 'ganho' particular de quem o realiza. Por exemplo, o trabalho de caseiro, que é exercido individualmente, se restringe, no máximo, à própria família nuclear, quando esta possui filhos menores de idade e estes de algum modo participam do trabalho.

Com o direcionamento cada vez maior para o veraneio, os moradores locais afastaram-se da vida coletiva e cotidiana do bairro, tais como comemorações locais, religiosidade, trabalhos comunitários - mutirão na roça, na construção de casas populares, na confecção e reparo de apetrechos do trabalho da pesca, curral e rede de pesca etc. Quanto mais se envolvem com os trabalhos externos - trabalhos de caseiros, por exemplo, ou outros com o veraneio - mais se ausentam da vida local da família e da vizinhança, pois passam a permanecer mais tempo na casa dos 'barões veranistas' e a freqüentar a vida urbana balnear, do que a suas respectivas casas residenciais e o que diz respeito ao bairro.

A proximidade com o mundo do veranista e a vida balnear impõe um ritmo novo nas relações sociais e de trabalho entre a familia e a vizinhança e amplia o nível de expectativa dos recursos disponíveis entre os moradores locais. Novos hábitos e novas preferências ampliam as expectativas e certas exigências de vida local: as casas, iguarias e tipos de preparos de alimentos, linguajar, modo de vestir, objetos de consumo pessoal, objetos domésticos, músicas, brincadeiras etc., são incorporadas e, aparentemente, passam a substituir o velho ritmo local. Mudam as relações entre a vizinhança, entre as pessoas e as coisas, entre os valores - os jovens locais entusiasmam-se pelo de fora - mudam as relações de casamento de afinidade e de compadrio entre os moradores do bairro.

Com o crescente envolvimento com a vida no balneário, os moradores locais da Prainha passam a privilegiar as relações com os 'barões veranistas', substituindo antigos laços que antes ligavam companheiros de pesca, parentes e afins, como as relações de compadrio tradicionalmente realizadas entre a vizinhança do bairro e que hoje passam a ser entre caseiros e patrões. Essa mudança, embora traga alguns ganhos materiais, como ajuda do padrinho/barão ao afilhado/caseiro, são ganhos aparentes de pouca significação econômica e social, pois na realidade o mesmo sistema que criou essas relações de trabalho, ampliou as necessidades, fazendo com que o fruto do trabalho seja insuficiente para garanti-las.

Embora seja de grande importância, este estudo não desenvolveu maior discussão teórico/política sobre os aspectos positivos e negativos da instalação do balneário; não se trata de verificar se as mudanças com o veraneio foram benéficas ou não para os moradores locais. No entanto, é preciso ter claro que a sociedade em questão não é uma sociedade isolada. Focalizou-se a relação entre pescadores tradicionais, caboclos e a sociedade moderna, representada pelos veranistas e turistas. Aborda-se sociedades modernas que, segundo Giddens (1995), são 'sociedades cerradas', sociedades da negação, que discriminam e separam por estereótipos diferentes sujeitos sociais.

Mais do que o interesse em verificar se a relação com o veraneio é benéfica ou não, todo esforço foi feito com o intuito de observar como os moradores locais articulam no seu cotidiano as injunções de mudança, ou seja, como estes pescadores do bairro da Prainha elaboram as mudanças processadas com

12 'Ganho' no sentido de oportunidade de trabalho e de remuneração, como se referem os moradores locais.

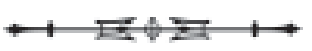


a nova relação de trabalho e o convívio com o veraneio. Este trabalho procurou descrever e analisar como certas inovações vindas com o veraneio e o turismo balnear, chegaram ao lugar de vida, ao modo de vida, ao cotidiano e à cultura de uma comunidade tradicional e popular e a seus grupos humanos, provocando alterações significativas, aparentemente irreversíveis e nem sempre desejadas. Assim, não se trata tanto de uma 'sociologia do turismo' e 'a sua influência sobre a vida dos pescadores', mas uma 'antropologia de como estas mudanças aconteceram e foram vividas, pensadas e verbalizadas por tais pescadores'. Em suma, esta pesquisa observou qual o trânsito entre saberes na prática cotidiana e como os moradores locais dialogam com suas tradições frente as mudanças engendradas pelo veraneio e o turismo balnear.

Deste modo, por tudo o que anteriormente já demonstrou-se, as mudanças nas relações de trabalho contribuíram para as transformações na vida social local, no âmbito familiar e sociocultural dos moradores do bairro da Prainha. Isto deve-se às mudanças nas relações de trabalho implicarem em novas representações sobre a natureza e na visão de mundo, consequentemente, nas formas de organização social. Através das relações de trabalho que ligam os homens entre si e com a natureza no seu cotidiano, nas suas diversas modalidades, é possível vislumbrar um desenho de mundo em que se representam na natureza.

Pode-se lembrar como os moradores locais evocam nas suas falas a história dos encantados, como garantia de uma inversão na ordem do mundo; mundo submerso $x$ mundo imerso, uma inversão de papéis que, de certa forma, lhes assegura legitimidade no lugar. Através das normas socialmente estabelecidas, é garantido o convívio e certo respeito à determinados lugares sob o olhar dos encantados.

A mesma reflexão pode ser feita para as observações do cotidiano dos caseiros. Os caseiros são a própria inversão do lugar; sem intermediários, são eles, que antes eram os proprietários das casas, e hoje são caseiros, na condição de empregados. Quando encarnam o lugar de segundo-dono, apenas reocupam o lugar que, de algum modo, também é seu.

Lendas e estórias contadas ao longo do trabalho de campo demonstram o conhecimento da história enriquecidos pela imaginação e crenças populares ligados ao sonho de tesouros submersos ou enterrados na cidade, bem como de uma povoação, verdadeira cidade submersa. Mostram a relação tempo e espaço, uma nova ordenação de mundo, com um tempo cíclico: que já foi e que é, como uma forma de resistência e sobrevivência frente ao impacto do turismo. Através das lendas e histórias contadas pela população local, observa-se uma certa consciência do processo de transformação e mudança pelo qual estão passando.

'Pescadores de sonhos' são os moradores do bairro da Prainha. São pescadores que abandonam o trabalho da pesca para se envolver nos trabalhos de caseiros e outros serviços voltados para o veraneio em busca de melhores condições de vida. Pescadores que pescam sonhos: sonhos capazes de inverter a ordem do mundo.

\section{REFERÊNCIAS}

ADRIÃO, Denise. 2003. Pescadores de sonhos: um olhar acerca da mudança nas relações de trabalho e na organização social entre as familias de pescadores diante do turismo balnear em Salinópolis-Pa. Tese (Doutorado). Unicamp, Campinas.

BECK, Anamaria. 1989. Pertence a mulher: mulher e trabalho em comunidades pesqueiras do Litoral de Santa Catarina. In: FÓRUM DE DISCUSSÃO SOBRE O UNIVERSO SOCIAL DA MULHER, A PESCA E SUA RELAÇÃO COM A ECOLOGIA. Natal: [s.n.]. Mimeo.

BHABHA, Homi K. 1998. O Local da Cultura. Belo horizonte: Ed. UFMG.

BHABHA, Homi K. 2001 [1998]. O Local da Cultura. Belo horizonte: Ed. UFMG; São Paulo: Cia das Letras.

BOURDIEU, Pierra. 1983. Gostos de classe e estilos de vida. In: ORTIZ, Renato (Org.). Bourdieu. São Paulo: Editora Ática. (Coleção Grandes Cientistas Sociais, n. 39).

BRANDÃO, Carlos R. 1995. Do Sertão à Cidade: quantos territórios? In: MESQUITA, Zilá; BRANDÃO, Carlos. Territórios do Cotidiano: uma introdução a novos olhares e experiências. Porto Alegre, Santa Cruz do Sul: Ed. Universidade, UFRGS, Ed. Universidade da Santa Cruz do Sul, UNISC.

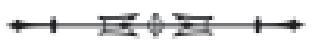


BRETON, Yvan et al. 1991. Pescadores y turistas a Sámara y el Coco: um amor de temporada? Quebec: Departament d'anthropologie, Dinámica social y comunidades pesqueras en el pacifico costarricence. (Université Laval, 1).

DESCOLA, Philippe. 1989. La Selva culta: simbolismo y praxis en la ecologia de los Achuar. Lima: Institut français d'études andines, IFEA - Abya-Yala. 468 p. il. Tomo 30.

DIAS, Daniella Maria dos Santos. 1996. Propriedade privada, política urbana e meio ambiente: considerações jurídicas sobre a ilha do Atalaia, no município de Salinópolis, Estado do Pará. Belém: UFPA, NUMA. (Estudos do NUMA, 8).

DIEGUES, Antonio Carlos Sant'Ana. 2000. A Imagem das Águas. São Paulo: HUCTTEC.

DUBOIS, Padre. 1949. Salinópolis (ex-Salinas) praia balnear oceânica. Belém: Oficinas gráficas da Revista da Veterinária. Ensaio de Monografia.

FRANZINELLE, E. 1992. Evolution of the geomorfology of the coast of the state of Pará, Brazil. In: PROST, M. T (Org.). Evolution des littoraux de Guyane et de la zone Caribe meridinale pedant le Quaternaire. Paris: Edition de (ORSTOM) L'Institut Français de Recherche Scientifique pour le Développement en Coopération.

FURTADO, Lourdes Gonçalves. 1987. Curralistas e Redeiros de Marudá: pescadores do litoral do Pará. Belém: Museu Paraense Emílio Goeldi.

FURTADO, Lourdes Gonçalves et al. (Org.). 1993. Povos das águas: realidade e perspectiva na Amazônia. Belém: Museu Paraense Emílio Goeldi.

GALVÃO, Eduardo. 1976 [1955]. Santos e Visagens: um estudo da vida religiosa de Itá, Baixo Amazonas. São Paulo: Editora Nacional.

GEERTZ, Clifford. 1998. O Saber Local: novos ensaios em antropologia interpretativa. Petrópolis: Vozes.

GIDDENS, Anthony. 2000. Modernidade. In: CONVERSAS com Anthony Giddens: o sentido da modernidade. Rio de janeiro: Editor FGV.

GIDDENS, Anthony. 2001. Modernidade, Totalitarismo e Teoria crítica. In: O ESTADO nação e a violência. São Paulo: Editora da Universidade de São Paulo. v. 2. (Clássicos, 22). Uma critica contemporânea ao materialismo histórico.

KRIPPENDORF, Jost. 1989. Sociologia do Turismo: para uma nova compreensão do lazer e das viagens. Rio de Janeiro: Civilização Brasileira.

LUCHIARI, Maria Tereza D. P. (Org.). 1999. O lugar do mundo contemporâneo: turismo e urbanização em Ubatuba, São Paulo. Tese (Doutorado em Ciências Sociais) - Universidade de Campinas. Mimeo.

MACEDO, Silvio Soares. 1993. Paisagem, urbanização e litoral: do éden à cidade. São Paulo: Universidade de São Paulo, Faculdade de Arquitetura e Urbanismo. (Livre Docência).

MADRUGA, Antonio Moacir. 1992. Litoralização: da fantasia de liberdade à modernidade autofágica. Dissertação (Mestrado) Departamento de Geografia da Faculdade de Filosofia, Letras e Ciências Humanas da Universidade de São Paulo.
MALDONADO, Simone Carneiro. 1994. Mestres e Mares: espaço e indivisão na pesca marítima. São Paulo: Ed. Anna Blume. (Selo Universidade, 7).

MANESCHY, Maria Cristina. 1993. Ajuruteua: uma comunidade pesqueira ameaçada. Belém: EDUFPA.

MANESCHY, Maria Cristina. 1990. A arte do pescador artesanal.

Boletim do Museu Paraense Emílio Goeldi, série de Antropologia, v. 6, n. 1, jun., p. 19-27.

MANESCHY, Maria Cristina. 1994. Uma presença discreta: a mulher na pesca. In: D'INCAO, M. A.; SILVEIRA, I. M. A Amazônia e a crise da modernização. Belém: Museu Paraense Emílio Goeldi. p. 251-258. (Coleção Eduardo Galvão).

MAUÉS, Raimundo Heraldo. 1990. Pesca e agricultura na Amazônia: a integração de uma comunidade rural ao modo de produção capitalista. Boletim do Museu Paraense Emílio Goeldi, série Antropologia, v. 6, n. 1, p. 29-40, jun.

MAUÉS, Raimundo Heraldo. 1995. Padres, pajés, santos e festas: catolicismo popular e controle eclesiástico, um estudo antropológico numa área do interior da Amazônia. Belém: Cejup.

MESQUITA, Zilá; BRANDÃO, Carlos. 1995. Territórios do Cotidiano: uma introdução a novos olhares e experiências. Porto Alegre, Santa Cruz do Sul: Ed. Universidade, UFRGS, Ed. Universidade da Santa Cruz do Sul, UNISC.

MOTTA-MAUÉS, Maria Angélica. 1999. Pesca de homem, peixe de mulher: repensando gênero na literatura acadêmica sobre comunidades pesqueiras no Brasil. Etnográfica, v. 3, n. 2, p. 377-399.

MOTTA-MAUÉS, Maria Angélica. 1993. Trabalhadeiras e Camarados: relações de gênero, simbolismo e ritualização numa comunidade Amazônica. Belém: UFPA, Centro de Filosofia e Ciências Humanas. (Coleção Igarapé).

NASCIMENTO, Maria Ivete Herculano. 1993. Homens e Peixes: o tempo na pesca artesanal. Dissertação (Mestrado) - Universidade Federal da Paraíba, Paraíba.

PENNER, Maria Eunice. 1984. A dialética da atividade pesqueira no nordeste Amazônico. Belém: UFPA.

RODRIGUES, Adyr Balastreri (Org.). 1999. Turismo e ambiente: reflexões e propostas. 2. ed. São Paulo: Hucitec. (Geografia: teoria e realidade, 41).

RODRIGUES, Adyr Balastreri (Org.). 2000. Turismo rural no Brasil: ensaio de uma tipologia. In: ALMEIDA, J. A.; RIDEDL, M. (Org.). Turismo Rural: ecologia, lazer e desenvolvimento. São Paulo: EDUSC.

SERRANO, C.; BRUHS, H. T.; DIEGUES, A. C. (Org.). 1999. Viagens à natureza: turismo, cultura e ambiente. São Paulo.

YÁZIGI, Eduardo et al. (Org.). 1999. Turismo: espaço, paisagem e cultura. 2. ed. São Paulo: Hucitec.

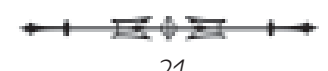

